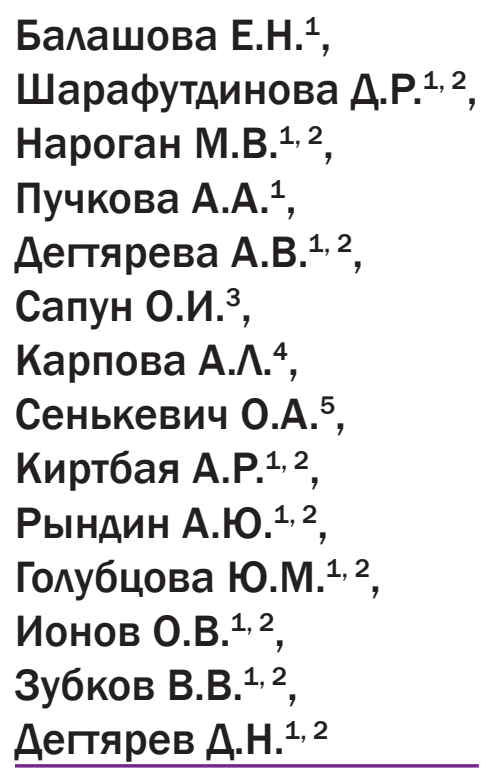

\begin{abstract}
${ }^{1}$ Федеральное государственное бюджетное учреждение "Национальный медицинский исследовательский центр акушерства, гинекологии и перинатологии имени академика В.И. Кулакова" Министерства зАравоохранения Российской Федерации, 117997, г. Москва, Российская Федерация

2 Федеральное государственное автономное образовательное учреждение высшего образования Первый Московский государственный медицинский университет имени И.М. Сеченова Министерства зАравоохранения Российской Федерации (Сеченовский Университет), 119991, г. Москва, Российская Федерация

${ }^{3}$ Федеральное государственное бюджетное образовательное учреждение высшего образования Кубанский государственный медицинский университет Министерства зАравоохранения Российской Федерации, 350063, г. Краснодар, Российская Федерация

${ }^{4}$ Федеральное государственное бюджетное образовательное учреждение высшего образования "Ярославский государственный медицинский университет" Министерства зАравоохранения Российской Федерации, 150000 , г. Ярославль, Российская Федерация

${ }^{5}$ Федеральное государственное бюджетное образовательное учреждение высшего образования "Аальневосточный государственный меАицинский университет" Министерства зАравоохранения Российской Федерации, 680000 , г. Хабаровск, Российская Федерация
\end{abstract}

В статье представлен обзор с рекомендациями по ведению недоношенных новорожденных с ранней анемией: определение, этиология, клиническая картина, диагностика и лечение данной патологии с научно-доказательной базой, алгоритмом действий врача и критериями качества оказания медицинской помощи.

Финансирование. Статья не имеет финансовой поддержки.

Конфликт интересов. Авторы заявляют об отсутствии конфликта интересов.

Вклад авторов. Работа с источниками литературы, написание текста - Балашова Е.Н., Шарафутдинова Д.Р., Нароган М.В., Пучкова А.А., Дегтярева А.В.; редактирование - Сапун 0.И., Карпова А.Л., Сенькевич О.А., Киртбая А.Р., Рындин А.Ю., Голубцова Ю.М., Ионов О.В., Зубков В.В., Дегтярев Д.Н.

Для цитирования: Балашова Е.Н., Шарафутдинова Д.Р., Нароган М.В., Пучкова А.А., Дегтярева А.В., Сапун О.И., Карпова А.Л., Сенькевич О.А., Киртбая А.Р., Рындин А.Ю., Голубцова Ю.М., Ионов О.В., Зубков В.В., Дегтярев Д.Н. Ранняя анемия недоношенных (клинические рекомендации) // Неонатология: новости, мнения, обучение. 2021. T. 9, № 3. C. 47-61. D0I: https://doi. org/10.33029/2308-2402-2021-9-3-47-61

Статья поступила в редакцию 06.09.2021. Принята в печать 30.09.2021.
Ключевые слова: анемия, недоношеннье новорожденнье, трансфузия, эритропоэтин

\title{
Early anemia of preterm infants (guideline)
}

Balashova E.N. ${ }^{1}$, Sharafutdinova D.R. ${ }^{1,2},{ }^{1}$ National Medical Research Center for Obstetrics, Gynecology Narogan M.V. ${ }^{1,2}$, Puchkova A.A. ${ }^{1}$, Degtyareva A.V. ${ }^{1,2}$, Sapun O.I. ${ }^{3}$, Karpova A.L. ${ }^{4}$, Senkevich O.A. ${ }^{5}$, Kirtbaya A.R. ${ }^{1,2}$, Ryndin A.Yu. ${ }^{1,2}$, Golubtsova Yu.M. ${ }^{1,2}$, Ionov O.V. ${ }^{1,2}$ Zubkov V.V. ${ }^{1,2}$, Degtyarev D.N. ${ }^{1,2}$ and Perinatology named after Academician V.I. Kulakov of the Ministry of Healthcare of the Russian Federation, 117997, Moscow, Russian Federation ${ }^{2}$ I.M. Sechenov First Moscow State Medical University of the Ministry of Healthcare of the Russian Federation (Sechenov University), 119991, Moscow, Russian Federation 
${ }^{3}$ Cuban State Medical University of Ministry of Healthcare of the Russian

Federation, 350063, Krasnodar, Russian Federation

${ }^{4}$ Yaroslavl State Medical University of the Ministry of Healthcare

of the Russian Federation, 150000, Yaroslavl, Russian Federation

${ }^{5}$ Far-East State Medical University» of the Ministry of Healthcare

of the Russian Federation, 680000 , Khabarovsk, Russian Federation

The article presents the guideline of management of the newborns with early anemia of preterm infants: definition, etiology, diagnostics and treatment of this disease with evidence based practice, algorithm of management and health care quality criteria.

Funding. No external funding.

Conflict of interest. The authors declare no conflict of interest.

Contribution. Work with literature sources, writing the text - Balashova E.N., Sharafutdinova D.R., Narogan M.V., Puchkova A.A., Degtyareva A.V.; article editing - Sapun 0.I., Karpova A.L., Senkevich 0.A., Kirtbaya A.R., Ryndin A.Yu., Golubtsova Yu.M., Ionov 0.V., Zubkov V.V., Degtyarev D.N.

For citation: Balashova E.N., Sharafutdinova D.R., Narogan M.V., Puchkova A.A., Degtyareva A.V., Sapun O.I., Karpova A.L., Senkevich 0.A., Kirtbaya A.R., Ryndin A.Yu., Golubtsova Yu.M., Ionov 0.V., Zubkov V.V., Degtyarev D.N. Early anemia of preterm infants (guideline). Neonatologiya: novosti, mneniya, obuchenie [Neonatology: News, Opinions, Training]. 2021; 9 (3): 47-61. D0I: https:// doi.org/10.33029/2308-2402-2021-9-3-47-61 (in Russian)

Received 06.09.2021. Accepted 30.09.2021.

\section{Список сокрашений}

АД - артериальное давление

ИВЛ - искусственная вентиляция легких

КОС - кислотно-основное состояние

МО - медицинская организация

НСГ - нейросонография

НЭК - некротизирующий энтероколит

ОГМ - обогатитель грудного молока

ОЖСС - общая железосвязывающая способность сыворотки крови

ОНМТ - очень низкая масса тела

ОПНиНД - отделение патологии новорожденных и недоношенных детей

ОРИТН - отделение реанимации и интенсивной терапии новорожденных

ОЦК - объем циркулирующей крови

РАН - ранняя анемия недоношенных

ПИТ - палата интенсивной терапии
УзИ - ультразвуковое исследование

чДД - частота дыхательных движений

чСС - частота сердечных сокращений

ЭСК - эритроцитсодержащие компоненты

ЭНМТ - экстремально низкая масса тела

ЭПО - эритропоэтин

$\mathrm{Hb}$ - гемоглобин

$\mathrm{HbA}$ - гемоглобин взрослого типа

$\mathrm{HbF}$ - фетальный гемоглобин

$\mathrm{Ht}$ - гематокрит

MCV - средний объем эритроцитов

MCH - среднее содержание гемоглобина в эритроците

MCHC - средняя концентрация гемоглобина в эритроците

RBC (red blood cells) - количество эритроцитов

RET-HE - гемоглобин в ретикулоцитах

SD - стандартное отклонение

\section{Термины и определения}

Анемия - гематологический синдром, характеризующийся снижением концентрации гемоглобина и/или гематокрита более чем на 2 стандартных отклонения (SD) от средних значений концентрации гемоглобина и/или гематокрита для данного постнатального возраста.

Ранняя анемия недоношенных - анемия, развивающаяся у недоношенных детей на 3-10-й неделе жизни.

\section{Краткая информашия}

\section{Определение}

Ранняя анемия недоношенных (РАН) - гематологический синдром, характеризующийся снижением гемоглобина и/или гематокрита более чем на 2SD от средних
Keywords: anemia, preterm infants, transfusion, erythropoietin значений гемоглобина и/или гематокрита для данного постнатального возраста у недоношенных детей, развивающаяся на 3-10-й неделе жизни [1, 2].

\section{Этиология и патогенез}

РАН имеет полиэтиологичный характер и связана с физиологическими факторами, обусловленными недоношенностью, и нефизиологическими факторами, к которым относятся кардиореспираторные нарушения после рождения, инфекционные заболевания и ятрогенные факторы [3].

К физиологическим факторам, связанными с недоношенностью, относятся:

1. Неадекватная продукция эритропоэтина (ЭП0) и его низкий уровень в плазме крови [4-7].

У недоношенных детей в послеродовом периоде уровень ЭПО значительно меньше, чем у доношенных, и существенно 
не меняется в течение первых 2 мес жизни [8]. Низкий ответ на тканевую гипоксию характерен для плодов и недоношенных детей, что является результатом переключения синтеза ЭПО из печени, менее чувствительной к гипоксии, в почки, более чувствительных - к гипоксии [3].

2. Меньшая продолжительность жизни эритроцитов (3060 дней).

3. Сдвиг кривой диссоциации кислорода влево в результате переключения синтеза гемоглобина с фетального (HbF), обладающего высоким сродством к кислороду, на гемоглобин взрослого (HbA), обладающего меньшим сродством к кислороду.

4. Постнатальное увеличение концентрации 2,3-дифосфоглицерата в эритроцитах, облегчающего высвобождение кислорода из гемоглобина.

5. Адаптивные сердечно-сосудистые механизмы, компенсирующие сниженную способность транспорта кислорода при анемии.

6. Увеличение объема циркулирующей крови в связи с быстрым ростом ребенка и увеличением массы тела [3].

К постнатальным и ятрогенным факторам относятся:

1. Тяжелая дыхательная и сердечно-сосудистая недостаточность.

2. Инфекционные заболевания (ранний и поздний неонатальный сепсис).

3. Флеботомические потери.

Флеботомические потери крови в связи с большей необходимостью лабораторного контроля состояния недоношенных детей также могут способствовать развитию РАН. У недоношенных новорожденных, особенно у детей с очень низкой (ОНМТ) и экстремально низкой массой тела (ЭНМТ), одной из основных причин развития анемии в первые недели жизни являются флеботомические потери при взятии крови на анализы. На первом месяце жизни у недоношенных детей с массой тела при рождении <1500 г флеботомические потери составляют от 3,8 до 22 мл/кг в неделю $[9,10]$.

4. Потери крови вследствие кровоизлияний и кровотечений.

5. Неадекватное поступление нутриентов (белок, витамины, минералы, калории) [3, 11].

Дефицит железа и витаминов в организме недоношенного ребенка усугубляет течение ранней анемии [12].

\section{Эпидемиология}

Наибольшая частота клинически значимой анемии отмечается в отделениях реанимации и интенсивной терапии новорожденных (ОРИТН), достигая 62-68\%.

Чаще всего анемия развивается у недоношенных детей (70\% общего количества новорожденных с анемией), особенно при гестационном возрасте $\leq 32$ нед, а также у детей, прооперированных в связи с врожденными пороками развития желудочно-кишечного тракта, сердца, и у больных с генерализованной внутриутробной инфекцией, неонатальным сепсисом $[1,9]$.

\section{Код по Международной классификации болезней 10-го} пересмотра

Р61.2 Анемия недоношенных.

\section{Классификация}

Отдельной классификации РАН не существует.

\section{Клиническая картина}

Клинические симптомы анемии неспецифичны: при осмотре обращают на себя внимание вялость, плохое сосание, «мраморность», бледность кожных покровов и слизистых в сочетании с различными нарушениями других органов и систем в зависимости от причины анемии; тахи-/ брадипноэ, апноэ, потребность в оксигенотерапии, снижение эффективности проводимой респираторной терапии, приводящее в том числе к увеличению параметров искусственной вентиляции легких (ИВЛ); сонливость или изменения неврологического состояния; тахикардия >180 в минуту, при аускультации сердца могут отмечаться приглушение тонов и систолический шум.

\section{$\triangle$ иагностика заболевания или состояния (группы заболеваний или состояний), меАицинские показания и противопоказания \\ к применению методов Аиагностики}

Критерии установления диагноза ранней анемии недоношенных

Диагноз «ранняя анемия недоношенных» может быть подтвержден, если выявлены лабораторные диагностические признаки анемии [13].

\section{Основные критерии диагностики ранней анемии недоношенных}

Снижение количества эритроцитов, уровня гемоглобина и/или гематокрита более чем на 2SD от средних значений эритроцитов, гемоглобина и/или гематокрита для данного постнатального возраста [1].

Уровни гемоглобина, гематокрита в зависимости от постнатального возраста ребенка представлены в табл. 1 [14].

\section{Вспомогательные диагностические критерии анемии новорожденных}

Показатели среднего объема эритроцитов (MCV), среднего содержания и средней концентрации гемоглобина в эритроците (МСН, $\mathrm{MCHC}$ ), ретикулоцитов (нормы ретикулоцитов у новорожденных 0,15-1,5\%) (табл. 2) [14].

РАН является нормоцитарной, нормохромной, гипорегенераторной.

Для РАН характерно снижение концентрации сывороточного ЭПО при нормальном уровне ферритина, трансферрина, железа. Референсные значения данных показателей зависят от типа используемого анализатора и могут несколько отличаться в различных медицинских организациях (М0).

\section{Жалобы и анамнез}

- Рекомендуется изучить анамнез матери для выявления факторов риска развития РАН $[14,15]$.

Уровень убедительности рекомендаций С (уровень достоверности доказательств 5). 
Таблица 1. Уровни венозного гемоглобина, гематокрита и эритроцитов у новорожденных и Аетей первых 6 мес жизни [13, 14] (модифицирована из Dallman P.R. et al., 1977, Girelli G. et al., 2015)

\begin{tabular}{|c|c|c|c|c|c|c|}
\hline \multirow[t]{2}{*}{ Возраст } & \multicolumn{2}{|c|}{ Гемоглобин, г/Аи } & \multicolumn{2}{|c|}{ Гематокрит, \% } & \multicolumn{2}{|c|}{ Эритроциты, ×10 $12 / \wedge$} \\
\hline & среднее & $-2 S D$ & среднее & $-2 S D$ & среднеє & $-2 S D$ \\
\hline Пуповина & 16,5 & 13,5 & 51 & 42 & 4,7 & 3,9 \\
\hline 1-3-й Аень & 18,5 & 14,5 & 56 & 45 & 5,3 & 4,0 \\
\hline 1 неА & 17,5 & 13,5 & 54 & 42 & 5,1 & 3,9 \\
\hline 2 неА & 16,5 & 12,5 & 51 & 39 & 4,9 & 3,6 \\
\hline $1 \mathrm{mec}$ & 14,0 & 10,0 & 43 & 31 & 4,2 & 3,0 \\
\hline $2 \mathrm{mec}$ & 11,5 & 9,0 & 35 & 28 & 3,8 & 2,7 \\
\hline 3-6 мес & 11,5 & 9,5 & 35 & 29 & 3,8 & 3,1 \\
\hline
\end{tabular}

Комментарии. К материнским факторам риска развития РАН относятся:

— наличие у матери анемии различной степени тяжести перед и во время беременности;

- многоплодная монохориальная беременность;

- наличие острой инфекции у матери или обострение хронической;

- преэклампсия;

- внутриматочные вмешательства во время беременности;

— наличие острой инфекции у матери или обострение хронической.

К неонатальным факторам относятся:

口 недоношенность;

- низкая масса тела при рождении;

- течение инфекционного процесса;

- флеботомические потери;

- геморрагический синдром.

\section{Физикальное обследование}

- Новорожденному с подозрением на врожденную анемию рекомендуется проведение визуального терапевтического осмотра $[1,15]$.

Уровень убедительности рекомендаций С (уровень достоверности доказательств 5).

Комментарии: см. раздел «Клиническая картина».

\section{Лабораторные диагностические исследования}

- Недоношенному ребенку с подозрением на анемию рекомендуется проведение общего (клинического) анализа крови с исследованием уровней эритроцитов, гемоглобина и гематокрита для определения дальнейшей тактики лечения [14, 16-18].

Уровень убедительности рекомендаций В (уровень достоверности доказательств 3).

Комментарии. Для достоверного определения гемоглобина и гематокрита оптимально использовать венозные показатели, поскольку при отечном или полицитемическом синдроме показатели капиллярной крови могут быть искажены.

— Для оценки нарушений газообмена, признаков тканевой гипоксии, метаболических нарушений и определения дальнейшей тактики симптоматической терапии у недоношенного новорожденного с признаками анемии, сопровождающимися дыхательными и/или гемодинамическими нарушениями, рекомендуется [17-26]:

- исследование кислотно-основного состояния (КОС); уровень убедительности рекомендаций С (уровень достоверности доказательств 4);

- газов крови; уровень убедительности рекомендаций В (уровень достоверности доказательств 3);

- уровня лактата в крови; уровень убедительности рекомендаций В (уровень достоверности доказательств 2).

Комментарии. Определение уровня лактата в крови зависит от возможностей лаборатории медицинской организации (М0).

- При подозрении на развитие и нарастание анемии у недоношенных новорожденных для дифференциальной диагностики рекомендуется исследование

Таблица 2. Показатели среднего объема эритроцитов (MCV), среАнего содержания и средней концентрации гемоглобина в эритроците (MCH, MCHC) у новорожденных и Аетей первых 6 мес жизни (венозная кровь) (модифицирована из Dallman P.R. et al., 1977; Girelli G. et al., 2015) [13, 14]

\begin{tabular}{|c|c|c|c|c|c|c|}
\hline \multirow[t]{2}{*}{ Возраст } & \multicolumn{2}{|c|}{ MCV, $\phi \Lambda$} & \multicolumn{2}{|c|}{ МСН, пг } & \multicolumn{2}{|c|}{$\mathrm{MCHC}, \mathrm{r} / \mathrm{AM}$} \\
\hline & среднее & $-2 S D$ & среднее & $-2 S D$ & среднее & $-2 S D$ \\
\hline Пуповина & 108 & 98 & 34 & 31 & 33 & 30 \\
\hline 1-3-й день & 108 & 95 & 34 & 31 & 33 & 29 \\
\hline $1 \mathrm{Hе} А$ & 107 & 88 & 34 & 28 & 33 & 28 \\
\hline 2 нед & 105 & 86 & 34 & 28 & 33 & 28 \\
\hline $1 \mathrm{Mec}$ & 104 & 85 & 34 & 28 & 33 & 29 \\
\hline $2 \mathrm{mec}$ & 96 & 77 & 30 & 26 & 33 & 29 \\
\hline 3-6 мес & 91 & 74 & 30 & 25 & 33 & 30 \\
\hline
\end{tabular}


уровня ретикулоцитов в крови, анализа крови биохимического общетерапевтического с определением концентраций железа, ферритина, трансферрина $[15,27-30]$.

Уровень убедительности рекомендаций С (уровень достоверности доказательств 4).

Комментарии. Референсные значения данных показателей зависят от типа используемого анализатора и могут несколько отличаться в различных МО. Следует помнить, что сывороточный ферритин является острофазным белком, поэтому при наличии у ребенка инфекционно-воспалительного процесса данный показатель может иметь нормальные или повышенные значения при существующем дефиците железа в организме. Напротив, показатель сывороточного трансферрина при наличии у ребенка инфекционно-воспалительного процесса бывает пониженным.

Снижение уровня гемоглобина в ретикулоцитах свидетельствует о латентном железодефиците. Референсные значения гемоглобина в ретикулоцитах (RET-HE) у недоношенных - 27-34 пг [31]. При возможности лабораторной диагностики в конкретной МО для диагностики РАН может использоваться определение концентрации сывороточного эритропоэтина.

- При ухудшении состояния во время и после гемотрансфузии недоношенному новорожденному рекомендуется исследование КОС и уровней калия и кальция в крови для выявления трансфузионных реакций и осложнений гемотрансфузии [26, 32, 33].

Уровень убедительности рекомендаций С (уровень достоверности доказательств 4).

Комментарии. Гиперкалиемия является следствием гемолиза эритроцитов. При выявлении гиперкалиемии трансфузию следует прекратить. Гипокальциемия, метаболический ацидоз или алкалоз, как правило, связаны с цитратной интоксикацией и требуют своевременной коррекции [33].

- После проведения гемотрансфузии у недоношенного новорожденного рекомендуется проведение общего (клинического) анализа крови и мочи не ранее чем через 2 ч и не позже 24 ч после гемотрансфузии для оценки эффективности и выявления осложнений $[34,35]$.

Уровень убедительности рекомендаций С (уровень достоверности доказательств 5).

Комментарии. Критерием эффективности гемотрансфузии является достижение целевых значений гематокрита и/или гемоглобина в венозной крови.

Инструментальные диагностические исследования

- Для исключения кровоизлияний во внутренние органы недоношенному новорожденному с признаками анемии рекомендуется проведение ультразвуковых исследований (УЗИ): нейросонографии (НСГ), УзИ брюшной полости (комплексного), почек и надпочечников [36-44].

Уровень убедительности рекомендаций В (уровень достоверности доказательств 2) для НСГ.

Уровень убедительности рекомендаций С (уровень достоверности доказательств 4) для УзИ брюшной полости, почек и надпочечников.
Лечение, включая медикаментозную и немедикаментозную терапию, диетотерапию, обезболивание, медицинские показания и противопоказания к применению методов лечения

\section{Консервативное лечение}

\section{Этиотропная и патогенетическая терапия}

- Недоношенному новорожденному с симптомами анемии и/или снижением уровня гемоглобина до значений, требующих коррекции, для достижения целевого уровня гемоглобина рекомендуется гемотрансфузия эритроцит-содержащих компонентов (ЭСК) крови с учетом потребности в проведении респираторной терапии [45-49].

Уровень убедительности рекомендаций А (уровень достоверности доказательств 1).

Комментарии. Показания для заместительной гемотрансфузии эритроцитсодержащих компонентов крови у недоношенных новорожденных представлены в табл. 3 [49].

Рекомендованные уровни гемоглобина в качестве критериев проведения трансфузии не могут применяться в случае крупных хирургических вмешательств, сепсиса, шока, кровотечения или симптомов, присущих анемии (тахикардия, тахипноэ) [14]. Особую группу составляют новорожденные с тяжелыми кардиореспираторными заболеваниями (пороки сердца, бронхолегочная дисплазия и т.п.) и дети на экстракорпоральной мембранной оксигенации. Для этой категории пациентов целесообразно поддерживать гематокрит на уровне $40 \%, \mathrm{Hb}$ - на уровне 120 г/л $[14,49,50]$.

Возможные риски и осложнения гемотрансфузии [51]

- Переливание неверного компонента ЭСК (по группе крови, резусу и т.д.).

- Острая/отсроченная трансфузионная реакция.

- Передача бактериальных и вирусных инфекций.

- Трансфузионно-ассоциированное осложнение «трансплантат против хозяина» - редкое, но часто смертельное состояние, которое предотвращается $\gamma$-облучением продуктов крови.

- Иммунный и неиммунный гемолиз.

- Метоболические нарушения (гиперкалиемия, гипокальциемия) и нарушение КОС крови.

- Острое повреждение легких, связанное с переливанием компонентов крови (TRALI), с развитием респираторных нарушений.

- Посттрансфузионная тромбоцитопеническая пурпура, при которой количество тромбоцитов катастрофически падает через 5-9 дней после переливания.

- Аллергические реакции.

- Перегрузка объемом.

- Апноэ.

- Нарушения сердечного ритма.

- Судороги.

- Эмболия (воздух/тромб).

- Гемодинамические нарушения.

- Инфекция. 
Таблица 3. Концентрации гемоглобина, при которых рекомендована трансфузия эритроцитсодержащего компонента крови у недоношенных детей, в зависимости от их респираторного статуса и постнатального возраста (по R. Whyte, H. Kirpalani, 2011) [49]

\begin{tabular}{|c|c|c|c|}
\hline $\begin{array}{l}\text { Возраст, } \\
\text { Ани }\end{array}$ & $\begin{array}{l}\text { Тип пробы } \\
\text { крови }\end{array}$ & $\begin{array}{c}\text { Новорожденные, нуждающиеся в респираторной } \\
\text { подАержке *, Hb, г/^ (Ht\%) }\end{array}$ & $\begin{array}{c}\text { Новорожденные без респираторной } \\
\text { поддержки, Нb, г/^ (Ht\%) }\end{array}$ \\
\hline $2-7$ & $\begin{array}{l}\text { Капиммярная } \\
\text { Венозная }\end{array}$ & $\begin{array}{l}\leq 115(35) \\
\leq 104\end{array}$ & $\begin{array}{l}\leq 100(30) \\
\quad \leq 90\end{array}$ \\
\hline $8-14$ & $\begin{array}{l}\text { Капиммярная } \\
\text { Венозная }\end{array}$ & $\begin{array}{l}\leq 100(30) \\
\quad \leq 90\end{array}$ & $\begin{array}{l}\leq 85(25) \\
\quad \leq 77\end{array}$ \\
\hline$\geq 15$ & $\begin{array}{l}\text { Капиммярная } \\
\text { Венозная }\end{array}$ & $\begin{array}{l}\leq 85(25) \\
\leq 77\end{array}$ & $\begin{array}{l}\leq 75(23) \\
\leq 68\end{array}$ \\
\hline
\end{tabular}

* - включает все виды респираторной терапии и подАержки адекватного самостоятельного дыхания, в том числе масочную или диф фузную подачу кислорода.

- Нестабильность температуры тела.

- Тромбоцитопения.

- Внутрижелудочковое кровоизлияние.

- Недоношенному новорожденному для коррекции анемии гемотрансфузия эритроцитсодержащих компонентов крови рекомендуется в объеме 10-20 мл/кг $[9,13,52,53]$.

Уровень убедительности рекомендаций С (уровень достоверности доказательств 2).

Комментарии. У недоношенного новорожденного без кровотечения объем трансфузируемого ЭСК в стандартных клинических ситуациях составляет 15 мл/кг $[9,14]$. Расчет трансфузируемого ЭСК также можно проводить по формуле и в этом случае объем ЭСК может превышать 20 мл/кг [14]:

$$
\text { Объем крови (мл) }=\frac{\begin{array}{c}
\text { целевой } \mathrm{Ht}-\mathrm{Ht} \\
\text { больного }
\end{array}}{\mathrm{Ht} \text { эск }} \times \begin{gathered}
\text { объем крови } \\
\text { новорожденного. }
\end{gathered}
$$

Объем крови недоношенного новорожденного 100 мл/кг. Нt целевой >0,35.

Во избежание осложнений массивной гемотрансфузии общий объем ЭСК не должен превышать $60 \%$ 0ЦК.

Рекомендуемая длительность трансфузии - не более 4 ч [54-57]. Гемотрансфузия у недоношенных новорожденных с ЭНМТ может проводится в 2 приема с интервалом 4 ч для уменьшения циркуляторной перегрузки и нарушений почечной функции.

- Во время гемотрансфузии и как минимум в течение 2 ч после недоношенному новорожденному рекомендуется проведение мониторинга частоты сердечных сокращений (ЧСС), артериального давления (АД), частоты дыхательных движений (ЧДД), степени насыщения гемоглобина кислородом, диуреза, цвета мочи, температуры тела для возможности выявления трансфузионных реакций и осложнений гемотрансфузии $[34,57,58]$.

Уровень убедительности рекомендаций С (уровень достоверности доказательств 5).

Комментарии. Трансфузию следует прекратить при появлении следующих побочных реакций [54]:

- тахикардия, брадикардия или аритмия;
- тахипноэ;

- увеличение систолического АД более чем на 15 мм рт.ст., если только это не является желательным эффектом;

- повышение температуры выше $38^{\circ} \mathrm{C}$ и/или $\geq 1{ }^{\circ} \mathrm{C}$;

- цианоз;

- кожная сыпь, крапивница, гиперемия;

- гематурия/гемоглобинурия.

- Для лечения ранней анемии недоношенных не рекомендуется рутинное назначение других антианемических препаратов (код АТХ В03ХА) [59].

Уровень убедительности рекомендаций В (уровень достоверности доказательств 1).

Комментарии. В группу «другие антианемические препараты» (код ATX В03XА) входят следующие препараты, применяемые у новорожденных: эпоэтин- $\alpha$ и - $\beta$. Также есть исследования по применению дарбопоэтина- $\alpha$ у новорожденных [59-62]. Схемы терапии эпоэтином- $\alpha$ (рекомбинантным человеческим эритропоэтином) в дозе $200 \mathrm{ME} / к г$ 3 раза в неделю внутривенно или подкожно до достижения целевых значений уровня гемоглобина и гематокрита, но не более 6 нед. Схема терапии эпоэтином- $\beta$ в дозе $250 \mathrm{ME} / к г$ 3 раза в неделю внутривенно или подкожно до достижения целевых значений уровня гемоглобина и гематокрита, но не более 6 нед. Режим дозирования дарбэпоэтина- $\alpha 10$ мкг/кг 1 раз в неделю $[60,63]$. При назначении препаратов следует руководствоваться инструкцией к препарату. Режим дозирования и способ введения препаратов могут отличаться в инструкциях различных производителей.

При нормализации уровня гемоглобина и гематокрита препарат отменяется.

Рекомендуется назначение эпоэтина- $\alpha$ или - $\beta$ (код ATX B03ХА) у глубоконедоношенных новорожденных гестационного возраста менее 31-й недели с целью повышения уровня гемоглобина на момент выписки из стационара [59, 64-68].

Уровень убедительности рекомендаций В (уровень достоверности доказательств 2).

Комментарии. Схемы лечения представлены в комментариях предыдущей рекомендации.

Лечебно-охранительный режим подразумевает создание оптимальных условий выхаживания недоношенных новорожденных. 
Важной составляющей при лечении анемии недоношенных является достаточное поступление энтерального (материнское молоко, обогащенное фортификатором, или смесь для недоношенных детей) либо в случаях интолерантности к энтеральному питанию парентерального белка не менее 3,5 г/кг в сутки [69].

\section{Профилактика и миспансерное наблюдение}

\section{Профилактика}

- Для профилактики анемии у новорожденного рекомендуется отсроченное пережатие и пересечение пуповины спустя 60-120 с при отсутствии необходимости в немедленном оказании помощи матери или ребенку [70-72].

Уровень убедительности рекомендаций А (уровень достоверности доказательств 1).

Комментарии. Альтернативой отсроченному пережатию может являться «сцеживание» пуповины. Рутинное применение «сцеживания» пуповины не рекомендуется в связи с отсутствием достаточных доказательств его безопасности у глубоконедоношенных новорожденных [70].

- Для профилактики анемии у недоношенного новорожденного рекомендуется минимизировать флеботомические потери и диагностические венепункции [73-76].

Уровень убедительности рекомендаций А (уровень достоверности доказательств 2).

Комментарии. Следует придерживаться обоснованного подхода к проведению дополнительных лабораторных исследований крови, использовать микрометоды определения минимально необходимых параметров крови, неинвазивный мониторинг газового состава крови и уровня билирубина при возможности в конкретной М0.

- Для профилактики анемии недоношенных не рекомендуется рутинное назначение других антианемических препаратов (код АТХ В03ХА) всем недоношенным новорожденным $[55,59]$.

Уровень убедительности рекомендаций В (уровень достоверности доказательств 1).

Комментарии. В группу «другие антианемические препараты» (код ATX В03ХА) входят следующие препараты, применяемые у новорожденных: эпоэтин- $\alpha$ и $-\beta$. Также есть исследования по применению дарбопоэтина- $\alpha$ у новорожденных [59-62]. Схемы терапии эпоэтином- $\alpha$ (рекомбинантным человеческим эритропоэтином): раннее назначение эпоэтина- $\alpha$ - с 3 сут жизни в дозе $200 \mathrm{ME} / к г$ 3 раза в неделю внутривенно или подкожно до достижения целевых значений уровня гемоглобина и гематокрита, но не более 6 нед. Схема терапии эпоэтином- $\beta$ - с 3 сут жизни в дозе $250 \mathrm{ME} /$ кг 3 раза в неделю внутривенно или подкожно до достижения целевых значений уровня гемоглобина и гематокрита, но не более 6 нед Режим дозирования дарбэпоэтина- $\alpha 10$ мкг/кг 1 раз в неделю $[60,63]$. При назначении препаратов следует руководствоваться инструкцией к препарату. Режим дозирования и способ введения препаратов могут отличаться в инструкциях различных производителей.

При нормализации уровня гемоглобина и гематокрита препараты отменяются.

- Рекомендуется назначать эпоэтин- $\alpha$ или - $\beta$ (код ATX В03ХА) у глубоконедоношенных новорожденных гестационного возраста менее 31 нед с целью повышения уровня гемоглобина на момент выписки из стационара [59, 64-68].

Уровень убедительности рекомендаций В (уровень достоверности доказательств2).

Комментарии. Схемы лечения см. в комментариях предыдущей рекомендации.

- Недоношенным новорожденным с ОНМТ и ЭНМТ для профилактики развития железодефицитного состояния рекомендуется назначение пероральных препаратов трехвалентного железа (код АТХ В03АВ) с 2 нед жизни [29, 77-82].

Уровень убедительности рекомендаций А (уровень достоверности доказательств 1).

Комментарии. Рекомендуемая доза пероральных препаратов трехвалентного железа (код АТХ В03АВ) для недоношенных новорожденных с ОНМТ и ЭНМТ составляет 2-3 мг/кг в сутки. Новорожденным с массой тела 15002000 г может рекомендоваться дотация пероральных препаратов трехвалентного железа (код АТХ В03АВ) железа (III) гидроксид полимальтозат в дозе 2 мг/кг в сутки, начиная с 2-4 нед жизни; новорожденным с массой тела при рождении 2000-2500 г - в дозе 1-2 мг/кг в сутки, начиная с 2-6 нед жизни. Лечение может продолжаться до 6-12 мес жизни в зависимости от индивидуальных показателей [83].

Терапия препаратами трехвалентного железа (код ATX В03АВ) проводится под контролем содержания гемоглобина, эритроцитов и ферритина в крови [83].

Референтные значения ферритина у недоношенных от 35 до 300 мкг/л представлены в табл. 4.

В случае снижения ферритина менее 35 мкг/л следует увеличить дозу препаратов железа до 3-4 (максимум до 6) мг/кг в сутки на ограниченный период. Длительной терапии препаратами железа в дозе >3 мг/кг в сутки следует избегать в связи с возможными неблагоприятными побочными эффектами. Повышение уровня ферритина более 300 мкг/л может встречаться в том числе при перегрузке железом вследствие многократных гемо-

Таблица 4. Рекомендуемые значения Аля Аиагностики избытка железа и железодефицита у детей до 2 лет (по M. Domellöf, 2017) [83]

\begin{tabular}{|l|c|c|c|c|}
\hline Ферритин, мкг/^ & Новорожденные & $\mathbf{2 ~ м е с ~}$ & $\mathbf{4 ~ м е с ~}$ & $\mathbf{6 - 2 4}$ мес \\
\hline Избыток железа & $>300$ & $>300$ & $>250$ & $>200$ \\
\hline Аефицит железа & $<35$ & $<40$ & $<20$ & $<10-12$ \\
\hline
\end{tabular}


трансфузий. В этом случае терапию препаратами железа следует прекратить до снижения уровня ферритина менее 300 мкг/л [83].

При проведении гемотрансфузий терапию препаратами трехвалентного железа (код ATX В03АВ) недоношенным детям рекомендуется продолжить, исключая случаи наличия сопутствующих гемолитических состояний. Если у ребенка имеются гемолитические нарушения, то при переливании крови рекомендуется отказаться от применения препаратов железа на 2 нед [81].

Во время терапии другими антианемическими препаратами (эпоэтин- $\alpha,-\beta$, дарбэпоэтин- $\alpha$ ) (код ATX В03ХА) повышается потребность в железе, поэтому при назначении эпоэтина- $\alpha,-\beta$, дарбэпоэтина- $\alpha$ (код АТХ В03ХА) рекомендуемая доза препаратов железа составляет до 6 мг/кг в сутки [83, 84].

Дефицит железа в критические периоды раннего постнатального развития мозга может иметь неблагоприятные последствия для нервно-психического развития недоношенного ребенка. Однако при назначении пероральных препаратов трехвалентного железа (код АТХ В03АВ) не следует забывать о побочных эффектах и опасности перегрузки железом. K побочным эффектам пероральных препаратов трехвалентного железа (код ATX В03АВ) относятся рвота, диарея, запор и другие заболевания желудочно-кишечного тракта. Избыток железа может оказывать негативное влияние на нервно-психическое развитие, кроме того, свободное сывороточное железо является потенциальным сильным окислителем, способствующим окислительному повреждению легких и сетчатки глаза недоношенных новорожденных $[77,80,81]$.

- Недоношенному ребенку с целью профилактики РАН не рекомендуется рутинное назначение витамина $\mathrm{E}$ [85-87].

Уровень убедительности рекомендаций В (уровень достоверности доказательств 2).

Комментарии. Недоношенные дети, особенно с ОНМТ и ЭНМТ, имеют дефицит витамина Е при рождении. Однако адекватное вскармливание ребенка (парентеральное/ энтеральное) позволяет уже в течение первых 6 нед жизни достичь пороговых значений витамина E в сыворотке крови [85]. Данные литературы также свидетельствуют о влиянии дополнительного применения витамина $\mathrm{E}$ на снижение гемолиза, повышение количества эритроцитов, показателя гемоглобина у недоношенных детей [86]. При использовании высоких доз препаратов железа (6 мг/кг в сутки), как правило, при применении эпоэтина- $\alpha,-\beta$, дарбэпоэтина- $\alpha$ (код АТХ В03ХА) развивается высокий риск перекисного окисления свободных радикалов железа наряду со сниженными запасами витамина $\mathrm{E}$ в первые 2 нед жизни, запуская каскад отрицательного влияния железо-индуцированного окислительного стресса и гемолиза. Таким образом, оправдано дополнительное применение витамина Е в дозе 15-25 МЕ/сут при использовании высоких доз препаратов железа в течение 6 нед [80, 84].

\section{Фолиевая кислота}

Физиологическая потребность у недоношенных детей в фолатах при энтеральном питании составляет 35100 мкг/кг [88].

В настоящее время установлено, что недоношенные дети имеют достаточную обеспеченность фолатами, если их матери получали добавки фолиевой кислоты (код ATX В03ВВ) во время беременности, а дети - оптимальное парентеральное и энтеральное питание [89-92]. При применении современных схем вскармливания нет риска развития дефицита фолатов у недоношенных детей, а бесконтрольное дополнительное назначение фолиевой кислоты (код ATX В03ВВ) может приводить к ее избыточному поступлению и чрезмерным концентрациям в крови недоношенных детей [88].

- Рекомендуется дополнительное назначение фолиевой кислоты (код АТХ В03ВВ) недоношенным новорожденным с целью профилактики анемии недоношенных в случае недостаточного поступления в организм фолатов (неоптимальное питание беременной, неоптимальное вскармливание недоношенного ребенка) в дозе до 100 мкг/сут $[88,89]$.

Уровень убедительности рекомендаций С (уровень достоверности доказательств 4).

\section{Диспансерное наблюдение}

Все недоношенные дети после выписки в течение первого года жизни должны наблюдаться у врача-педиатра как группа риска по развитию анемии. При наличии рефрак-

Таблица 5. Кратность гематологического обследования в зависимости от концентрации гемоглобина на амбулаторном этапе

\begin{tabular}{|c|c|c|c|}
\hline $\begin{array}{l}\text { Аабораторный } \\
\text { показатель }\end{array}$ & $\begin{array}{c}\text { Нb от нижней границы возрастной } \\
\text { нормы до } 90 \text { г/^ }\end{array}$ & Hb 70-89 г/^ & $\mathrm{Hb}<70$ г/^ \\
\hline $\begin{array}{l}\text { Hb, Нt, эритроциты, } \\
\text { MCV, МСH, МСНC, } \\
\text { RET-HE, ретикулоциты, } \\
\%\end{array}$ & 1 раз в 3-4 неА & $\begin{array}{l}1 \text { раз } \\
\text { в 10-14 Аней }\end{array}$ & $\begin{array}{l}1 \text { раз в 5-7 Аней. } \\
\text { При снижении гемоглобина <65-70 г/^ } \\
\text { и наличии сопутствующей патологии } \\
\text { показана госпитализация }\end{array}$ \\
\hline $\begin{array}{l}\text { Сывороточный } \\
\text { ферритин, } \\
\text { трансферрин (или } \\
\text { ожСС), сывороточное } \\
\text { железо }\end{array}$ & $\begin{array}{l}1 \text { раз в } 3 \text { мес Аля оценки содержания } \\
\text { запасов железа в организме с целью } \\
\text { прекращения/продолжения применения } \\
\text { препарата железа в ^ечебной/ } \\
\text { профилактической дозе }\end{array}$ & $\begin{array}{l}1 \text { раз в } 2 \text { мес } \\
\text { с целью } \\
\text { коррекции } \\
\text { дозы препарата } \\
\text { железа }\end{array}$ & $\begin{array}{l}1 \text { раз в месяц с целью коррекции Аозы } \\
\text { препарата железа }\end{array}$ \\
\hline
\end{tabular}


терного гематологического симптомокомплекса анемии или клинико-гематологического симптомокомплекса прогрессирующей анемии должны консультироваться врачом-гематологом. Кратность обследования зависит от степени выраженности анемии (представлена в табл. 5).

Следует помнить, что важной составляющей диспансерного наблюдения недоношенных детей с анемией является адекватное вскармливание в соответствии с современными принципами вскармливания недоношенных детей [93].

- Глубоконедоношенным новорожденным с целью профилактики железодефицита на амбулаторном этапе рекомендуется назначение пероральных препаратов трехвалентного железа (код АТХ В03АВ) [29, 82, 93, 94].

Уровень убедительности рекомендаций А (уровень достоверности доказательств 1).

Комментарии. Доза пероральных препаратов трехвалентного железа (код АТХ В03АВ) для глубоконедоношенных детей на амбулаторном этапе, как правило, составляет 2-3 мг/кг в сутки. Детям, находящимся на грудном вскармливании и не получающим обогатитель грудного молока (ОГМ), дотацию препаратами железа проводить до 6 скорректированных месяцев или до введения прикорма или смесей, обогащенных железом. Детям на искусственном вскармливании, не получающим обогащенные железом смеси, дотация проводится до введения прикорма. Более длительный прием препаратов железа показан детям с низкими сывороточными уровнями железа и ферритина (см. табл. 4). Дети, получающие специализированную смесь для недоношенного ребенка или ОГМ и имеющие нормальный уровень железа и ферритина в крови, не нуждаются в дополнительной дотации препаратов железа с профилактической целью. В случае развития железодефицитной анемии ребенок должен получать препараты железа в лечебной дозе 4-6 мг/кг в сутки в зависимости от степени тяжести анемии.

\section{Организашия оказания медишинской помоши}

Гемотрансфузия новорожденным проводится в стационарных условиях.

Показания к выписке пациента из медицинской организации:

1. Стабильное удовлетворительное состояние ребенка.

2. Стабилизация лабораторных показателей и отсутствие показаний для гемотрансфузии.

3. Отсутствие противопоказаний к выписке.

\section{Аополнительная информашия}

Прогноз заболевания при отсутствии сопутствующих заболеваний, как правило, благоприятный. В зависимости от тяжести анемии возможно тяжелое поражение внутренних органов, в частности острое повреждение почек. Прогноз зависит от сопутствующих заболеваний.

Дифференциальную диагностику следует проводить со следующими заболеваниями и состояниями.

Анемии другой этиологии: врожденные и приобретенные, возникающие в результате редукции эритропоэза; возникающие в результате повышенной деструкции клеток эритроидного ряда; возникающие в результате кровопотери.

Организация-разработчик: Общероссийская общественная организация содействия развитию неонатологии «Российское общество неонатологов» (РОН).

Критерии оценки качества меАицинской помощи

\begin{tabular}{|c|c|c|}
\hline № & Критерии качества & $\begin{array}{c}\text { Оценка } \\
\text { выполнения }\end{array}$ \\
\hline 1 & Выполнен визуальный терапевтический осмотр & Аа/нет \\
\hline 2 & Выполнен общий (клинический) анализ крови после рожАения & $\mathrm{Aa} /$ нет \\
\hline 3 & $\begin{array}{l}\text { Выполнено исследование кислотно-основного состояния, газов крови и лактата крови при наличии } \\
\text { дыхательных и гемодинамических нарушений }\end{array}$ & Аа/нет \\
\hline 4 & Выполнена НСг & $\mathrm{Aa} / \mathrm{нет}$ \\
\hline 5 & Выполнено УЗИ брюшной полости (комплексное), почек и надпочечников & Аа/нет \\
\hline 6 & Выполнено исслеАование уровня ретикулоцитов в крови & Аа/нет \\
\hline 7 & $\begin{array}{l}\text { Выполнен анализ крови биохимический общетерапевтический с определением уровня железа, ферритина, } \\
\text { трансферрина }\end{array}$ & Аа/нет \\
\hline 8 & $\begin{array}{l}\text { Выполнена гемотрансфузия при снижении уровня гемоглобина Ао значений, требующих } \\
\text { коррекции }\end{array}$ & Аа/нет \\
\hline 9 & $\begin{array}{l}\text { Выполнен мониторинг ЧСС, АА, ЧАА, степени насыщения гемоглобина кислородом, Аиуреза, цвета мочи, } \\
\text { температуры тела во время и в течение } 2 \text { ч после гемотрансфузии }\end{array}$ & Аа/нет \\
\hline 10 & $\begin{array}{l}\text { Выполнено исслеАование кислотно-основного состояния и уровней калия и кальция в крови во время } \\
\text { и после гемотрансфузии при ухудшении состояния }\end{array}$ & $\mathrm{Aa} /$ нет \\
\hline 11 & $\begin{array}{l}\text { Выполнено исслеАование общего (клинического) анализа крови и мочи не ранее чем через } 2 \text { ч и не позже } \\
24 \text { ч после гемотрансфузии }\end{array}$ & Аа/нет \\
\hline 12 & Выполнено назначение препаратов железа & Аа/нет \\
\hline 13 & $\begin{array}{l}\text { Выполнено отсроченное пережатие и пересечение пуповины спустя 60-120 с при отсутствии } \\
\text { необходимости в немедленном оказании помощи матери или ребенку }\end{array}$ & Аа/нет \\
\hline
\end{tabular}

Расшифровка аббревиатур дана в начале статьи. 


\section{Приложение. А^горитмы Аействий врача}

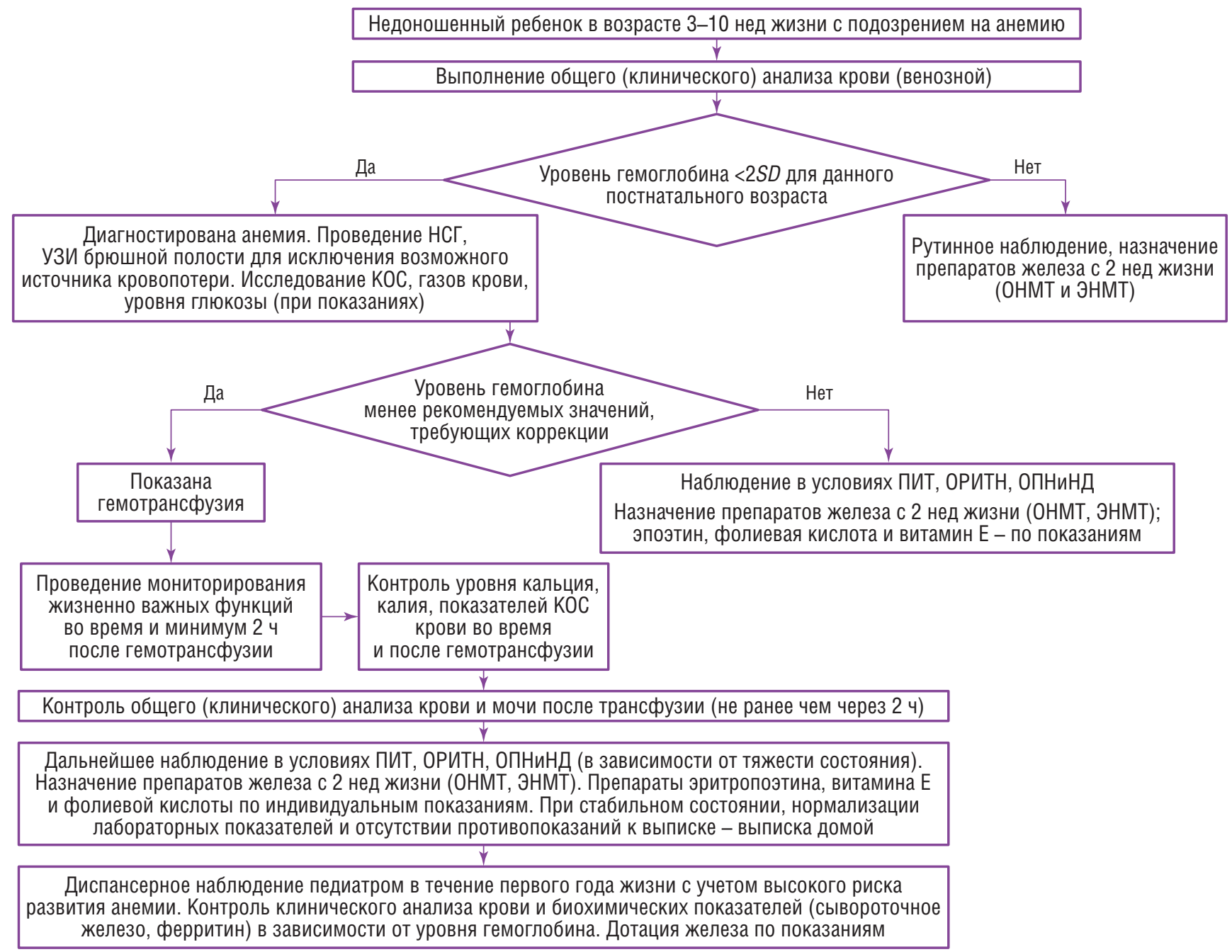

\section{CBEAEHИЯ ОБ АBTOPAX}

Балашова Екатерина Николаевна (Ekaterina N. Balashova) - кандидат медицинских наук, доцент кафедры неонатологии ФГБУ «НМИЦ АГП им. акад. В.И. Кулакова» Минздрава России, ведущий научный сотрудник ОРИТ имени проф. А.Г. Антонова Института неонатологии и педиатрии ФГБУ «НМИЦ АГП им. акад. В.И. Кулакова» Минздрава России, член Совета Российского общества неонатологов, Москва, Российская Федерация

E-mail: katbal99@gmail.com

https://orcid.org/0000-0002-3741-0770

Шарафутдинова Дияна Рашидовна (Diana R. Sharafutdinova) - кандидат медицинских наук, врач - анестезиолог-реаниматолог ОРИТ имени проф. А.Г. Антонова Института неонатологии и педиатрии ФГБУ «НМИЦ АГП им. акад. В.И. Кулакова» Минздрава России, ассистент кафедры неонатологии Клинического института детского здоровья им. Н.Ф. Филатова ФГАОУ В0 Первый МГмУ им. И.М. Сеченова Минздрава России (Сеченовский Университет), член Совета Российского общества неонатологов, Москва, Российская Федерация

E-mail: dikarush@gmail.com

https://orcid.org/0000-0001-9626-5481

Нароган Марина Викторовна (Marina V. Narogan) - доктор медицинских наук, ведущий научный сотрудник отделения патологии новорожденных и недоношенных детей Института неонатологии и педиатрии ФГБУ «НМИЦ АГП им. акад. В.И. Кулакова» Минздрава России, профессор кафедры неонатологии Клинического института детского здоровья им. Н.Ф. Филатова ФГАОУ ВО Первый МГмУ им. И.М. Сеченова Минздрава России (Сеченовский Университет), член Совета Российского общества неонатологов, Москва, Российская Федерация

E-mail: m_narogan@oparina4.ru

https://orcid.org/0000-0002-3160-905X 
Пучкова Анна Александровна (Anna A. Puchkova) - кандидат медицинских наук, заведующий по клинической работе КдЦ Института неонатологии и педиатрии ФГБУ «НМИЦ АГП им. акад. В.И. Кулакова» Минздрава России, член Российского общества неонатологов, Москва, Российская Федерация

E-mail:a_puchkova@oparina4.ru

https://orcid.org/0000-0001-6897-247X

Дегтярева Анна Владимировна (Anna V. Degtyareva) - доктор медицинских наук, профессор, заведующий отделом педиатрии Института неонатологии и педиатрии ФГБУ «НМИЦ АГП им. акад. В.И. Кулакова» Минздрава России, профессор кафедры неонатологии Клинического института детского здоровья им. Н.Ф. Филатова ФГАОУ ВО Первый МГМУ им. И.М. Сеченова Минздрава России (Сеченовский Университет), член Совета Российского общества неонатологов, Москва, Российская Федерация

E-mail: a_degtyareva@oparina4.ru

https://orcid.org/0000-0003-0822-751X

Сапун Ольга Ильинична (Olga I. Sapun) - заведующий ОРИТН № 2 ДККБ г. Краснодар, главный внештатный неонатолог Минздрава Краснодарского края, ассистент кафедры педиатрии с курсом неонатологии Кубанского государственного медицинского университета, член Совета Российского общества неонатологов, Краснодар, Российская Федерация

E-mail:sapuno@mail.ru

Карпова Анна Львовна (Anna L. Karpova) - кандидат медицинских наук, заместитель главного врача по детству ГБУз Калужской области «Калужская областная клиническая больница», главный внештатный неонатолог Минздрава Калужской области, ассистент кафедры ФГБОУ ВО ЯГмУ Минздрава России, член Совета Российского общества неонатологов, Ярославль, Российская Федерация

E-mail: anna1409@mail.ru

https://orcid.org/0000-0002-1024-0230

Сенькевич Ольга Александровна (Olga A. Senkevich) - доктор медицинских наук, профессор, заведующий кафедрой педиатрии, неонатологии и перинатологии с курсом неотложной медицины Института непрерывного профессионального образования и аккредитации ФГБОУ ВО ДВГМУ Минздрава России, член Совета Российского общества неонатологов, Хабаровск, Российская Федерация

E-mail: senkevicholga@ya.ru

https://orcid.org/0000-0003-4195-2350

Киртбая Анна Ревазиевна (Anna R. Kirtbaya) - кандидат медицинских наук, заведующий по клинической работе ОРИт имени проф. А.Г. Антонова Института неонатологии и педиатрии ФГБУ «НМИЦ АГП им. акад. В.И. Кулакова» Минздрава России, доцент кафедры неонатологии Клинического института детского здоровья им. Н.Ф. Филатова ФГАОУ ВО Первый МГмУ им. И.М. Сеченова Минздрава России (Сеченовский Университет), член Российского общества неонатологов, Москва, Российская Федерация

E-mail: a_kirtbaya@oparina4.ru

https://orcid.org/0000-0002-7628-8157

Рындин Андрей Юрьевич (Andrey Yu. Ryndin) - кандидат медицинских наук, старший научный сотрудник ОРИТ имени проф. А.Г. Антонова Института неонатологии и педиатрии ФГБУ «НМИЦ АГП им. акад. В.И. Кулакова» Минздрава России, доцент кафедры неонатологии Клинического института детского здоровья им. Н.Ф. Филатова ФГАОУ ВО Первый МГМУ им. И.М. Сеченова Минздрава России (Сеченовский Университет), член Совета Российского общества неонатологов, Москва, Российская Федерация

E-mail: a_ryndin@oparina4.ru

https://orcid.org/0000-0001-5560-8759

Голубцова Юлия Марковна (Yulia M. Golubtsova) - заведующий учебной частью, доцент кафедры неонатологии Клинического института детского здоровья им. Н.Ф. Филатова ФГАОУ ВО Первый МГМУ им. И.М. Сеченова Минздрава России (Сеченовский Университет), Москва, Российская Федерация

E-mail:yugolubtsova@yandex.ru

https://orcid.org/0000-0002-2288-1721

Ионов Олег Вадимович (Oleg V. Ionov) - доктор медицинских наук, заведующий ОРИТ им. проф. А.Г. Антонова Института неонатологии и педиатрии ФГБУ «НМИЦ АГП им. акад. В.И. Кулакова» Минздрава России, доцент кафедры неонатологии Клинического института детского здоровья им. Н.Ф. Филатова ФГАОУ ВО Первый МГМУ им. И.М. Сеченова Минздрава России (Сеченовский Университет), председатель Российского общества неонатологов, Москва, Российская Федерация

E-mail: o_ionov@oparina4.ru

https://orcid.org/0000-0002-4153-133X

Зубков Виктор Васильевич (Viktor V. Zubkov) - доктор медицинских наук, директор Института неонатологии и педиатрии, заведующий кафедрой неонатологии ФГБУ «НМИЦ АГП им. акад. В.И. Кулакова» Минздрава России, профессор кафедры неонатологии Клинического института детского здоровья им. Н.Ф. Филатова ФГАОУ ВО Первый МГМУ им. И.М. Сеченова Минздрава России (Сеченовский Университет), член Совета Российского общества неонатологов, Москва. Российская Федерация

E-mail:v_zubkov@oparina4.ru

https://orcid.org/0000-0001-8366-5208 
Дегтярев Дмитрий Николаевич (Dmitriy N. Degtyarev) - доктор медицинских наук, профессор заместитель директора по научной работе ФГБУ «НМИЦ АГП им. акад. В.И. Кулакова» Минздрава России, заведующий кафедрой неонатологии Клинического института детского здоровья им. Н.Ф. Филатова ФГАОУ ВО Первый МГМУ им. И.М. Сеченова Минздрава России (Сеченовский Университет), председатель Этического комитета Российского общества неонатологов, Москва, Российская Федерация

E-mail: d_degtiarev@oparina4.ru

https://orcid.org/0000-0001-8975-2425

\section{ヘИТЕРАТУРА}

1. Colombatti R., Sainati L., Trevisanuto D. Anemia and transfusion in the neonate // Semin. Fetal Neonatal Med. 2016. Vol. 21, N 1. P. 2-9.

2. Сахарова Е.С., Кешишян Е.С., Алямовская Г.А. Анемия недоношенных детей. Патогенез, Аиагностика, мечение и профилактика // МеАицинский совет. 2015. № 6. С. 10-17.

3. Widness J.A. Pathophysiology of anemia during the neonatal period, including anemia of prematurity // Neoreviews. 2008. Vol. 9, N 11. P. 520 525.

4. Luchtman-Jones L., Schwartz W.D. The blood and hematopoietic system // Neonatal-Perinatal Medicine. Disorders of Fetus and Infant. 7th ed. / eds A.A. Fanaroff, R.J. Martin. St Louis : Mosby, 2002. P. 11821254.

5. Widness J.A. Pathophysiology, diagnosis, and prevention of neonatal anemia // Neoreviews. 2000. Vol. 1, N 4. P. 61

6. Папаян А.В., Жукова ^.Ю. Анемии у Аетей : руководство А^я врачей. Санкт-Петербург : Питер, 2001. 384 с. (Серия “Современная меАицина"). ISBN 5-272-00364-0.

7. Dallman P.R. Blood and blood-forming tissues // Pediatrics. 16th ed. / ed. A. Rudolph. New York : Appleton-Century-Crofts, 1977. P. 1111.

8. Brown M.S. et al. Decreased response of plasma immunoreactive erythropoietin to "available oxygen" in anemia of prematurity // J. Pediatr. 1984. Vol. 105, N 5. P. 793-798.

9. New H.V. et al. Guidelines on transfusion for fetuses, neonates and older children // Br. J. Haematol. 2016. Vol. 175, N 5. P. 784-828.

10. Von Lindern J.S., Lopriore E. Management and prevention of neonatal anemia: current evidence and guidelines // Expert Rev. Hematol. 2014. Vol. 7, N 2. P. 195-202.

11. de Freitas B.A.C. et al. Micronutrient supplementation adherence and influence on the prevalences of anemia and iron, zinc and vitamin a deficiencies in preemies with a corrected age of six months // Clinics. 2016. Vol. 71, N 8. P. 440-448.

12. Aher S., Malwatkar K., Kadam S. Neonatal anemia // Semin. Fetal Neonatal Med. 2008. Vol. 13, N 4. P. 239-247.

13. Dallman P.R. Anemia of prematurity // Annu. Rev. Med. 1981. Vol. 32. P. $143-160$

14. Girelli G. et al. Recommendations for transfusion therapy in neonatology // Blood Transfus. 2015. Vol. 13, N 3. P. 484-497.

15. Bizzarro M.J., Colson E., Ehrenkranz R.A. Differential diagnosis and management of anemia in the newborn // Pediatr. Clin. North Am. 2004. Vol. 51. P. $1087-1107$.

16. Jopling J. et al. Reference ranges for hematocrit and blood hemoglobin concentration during the neonatal period: data from a multihospital health care system // Pediatrics. 2009. Vol. 123, N 2. P. e333-e337.

17. Obladen M., Sachsenweger M., Stahnke M. Blood sampling in very low birth weight infants receiving different levels of intensive care // Eur. J. Pediatr. 1988. Vol. 147, N 4. P. 399-404.

18. Madsen L.P. et al. Impact of blood sampling in very preterm infants // Scand. J. Clin. Lab. Invest. 2000. Vol. 60, N 2. P. 125-132.

19. Takahashi D. et al. Effect of transfusion on the venous blood lactate level in very low-birthweight infants // Pediatr. Int. 2009. Vol. 51, N 3. P. 321-325

20. Dani C. et al. Effects of red blood cell transfusions during the first week of life on acid-base, glucose, and electrolytes in preterm neonates // Transfusion. 2008. Vol. 48, N 11. P. 2302-2307.

21. Nadeem M., Clarke A., Dempsey E.M. Day 1 serum lactate values in preterm infants less than 32 weeks gestation // Eur. J. Pediatr. 2010. Vol. 169, N 6. P. 667-670.

22. Izraeli S. et al. Lactic acid as a predictor for erythrocyte transfusion in healthy preterm infants with anemia of prematurity // J. Pediatr. 1993. Vol. 122, N 4. P. 629-631.
23. Ross M.P., Christensen R.D., Rothstein G., Koenig J.M., Simmons M.A., Noble N.A. et al. A randomized trial to develop criteria for administering erythrocyte transfusions to anemic preterm infants 1 to 3 months of age // J. Perinatol. 1989. Vol. 9, N 3. P. 246-253.

24. Kanmaz H.G. et al. Effects of red cell transfusion on cardiac output and perfusion index in preterm infants // Early Hum. Dev. 2013. Vol. 89, N 9. P. 683-686.

25. Dallman M.D. et al. Changes in transfusion practice over time in the PICU // Pediatr. Crit. Care Med. 2013. Vol. 14, N 9. P. 843850.

26. Abdelghaffar $\mathrm{S}$. et al. Red blood transfusion in preterm infants: changes in glucose, electrolytes and acid base balance // Asian J. Transfus. Sci. 2012. Vol. 6, N 1. P. 36-41.

27. Wang M. Iron deficiency and other types of anemia in infants and children // Am. Fam. Physician. 2016. Vol. 93, N 4. P. 270-278.

28. Joy R. et al. Early versus late enteral prophylactic iron supplementation in preterm very low birth weight infants: a randomised controlled trial // Arch. Dis. Child. Fetal Neonatal Ed. 2014. Vol. 99, N 2. P. F105-F109.

29. McCarthy E.K., Dempsey E.M., Kiely M.E. Iron supplementation in preterm and low-birth-weight infants: a systematic review of intervention studies // Nutr. Rev. 2019. Vol. 77, N 12. P. 865-877.

30. Schiza V. et al. Serum transferrin receptor, ferritin, and reticulocyte maturity indices during the first year of life in "large" preterm infants // Eur. J. Haematol. 2007. Vol. 79, N 5. P. 439-446.

31. Lorenz L. et al. Reference ranges of reticulocyte haemoglobin content in preterm and term infants: a retrospective analysis // Neonatology. 2017. Vol. 111, N 3. P. 189-194.

32. Diab Y.A., Wong E.C.C., Luban N.L.C. Massive transfusion in children and neonates // Br. J. Haematol. 2013. Vol. 161, N 1. P. 15-26.

33. Sihler K.C., Napolitano L.M. Complications of massive transfusion // Chest. 2010. Vol. 137, N 1. P. 209-220.

34. Приказ Минзарава России от 02.04.2013 № 183н “Об утвержАении правил клинического использования донорской крови и (или) ее компонентов" (зарегистрировано в Минюсте России. 2013).

35. MacDonald M.G., Ramasethu J.R.-B.K. Atlas of Procedures in Neonatology. 5th ed. Lippincott Williams and Wilkins, Wolter Kluwer, 2013. $429 \mathrm{p}$.

36. Mozzini C. et al. Ultrasound as first line step in anaemia diagnos tics // Mediterr. J. Hematol. Infect Dis. 2019. Vol. 11, N 1. P. 1-10.

37. Singh Y. et al. International evidence-based guidelines on Point of Care Ultrasound (POCUS) for critically ill neonates and children issued by the POCUS Working Group of the European Society of Paediatric and Neonatal Intensive Care (ESPNIC) // Crit. Care. 2020. Vol. 24, N 1. P. 1-16.

38. Joshi S., Mulinge I., Kamat M. An extremely premature neonate with severe anemia // J. Neonatal Surg. 2017. Vol. 6, N 2. P. 33.

39. Mutlu M. et al. Adrenal hemorrhage in newborns: a retrospective study // World J. Pediatr. 2011. Vol. 7, N 4. P. 355-357.

40. Kluckow M., Evance N. Low superior vena cava flow and intraventricular haemorrhage in preterm infants. // Arch. Dis. Child. Feta Neonatal Ed. 2000. Vol. 82, N 3. P. 188-194.

41. Papile L.A. et al. Incidence and evolution of subependymal and intraventricular hemorrhage: a study of infants with birth weights less than 1,500 gm // J. Pediatr. 1978. Vol. 92, N 4. P. 529-534.

42. Hintz S.R. et al. Interobserver reliability and accuracy of cranial ultrasound scanning interpretation in premature infants // J. Pediatr. 2007 Vol. 150, N 6. P. 592-596.

43. Toti M.S. et al. Adrenal hemorrhage in newborn: how, when and why- from case report to literature review // Ital. J. Pediatr. 2019. Vol. 45 , N 1. P. 1-8. 
44. Azarow K. et al. Multidisciplinary evaluation of the distended abdomen in critically ill infants and children: the role of bedside sonography // Pediatr. Surg. Int. 1998. Vol. 13, N 5-6. P. 355-359.

45. Sweet D.G. et al. European Consensus Guidelines on the Management of Respiratory Distress Syndrome - 2019 Update // Neonatology. 2019. Vol. 115, N 4. P. 432-450.

46. Von Lindern J.S. et al. Long-term outcome in relationship to neonatal transfusion volume in extremely premature infants: a comparative cohort study // BMC Pediatr. 2011. Vol. 11. P. 48.

47. Venkatesh V. et al. How we decide when a neonate needs a transfusion // Br. J. Haematol. 2013. Vol. 160, N 4. P. 421-433.

48. Venkatesh V. et al. The safety and efficacy of red cell transfusions in neonates: a systematic review of randomized controlled trials // $\mathrm{Br}$. J. Haematol. 2012. Vol. 158, N 3. P. 370-385.

49. Whyte R., Kirpalani H. Low versus high haemoglobin concentration threshold for blood transfusion for preventing morbidity and mortality in very low birth weight infants // Cochrane Database Syst. Rev. 2011 Vol. 11. CD000512.

50. Strauss R.G. Anaemia of prematurity: pathophysiology and treatment // Blood Rev. 2010. Vol. 24, N 6. P. 221-225.

51. Nurse S.N. Red Blood Cell Transfusion for Neonates - Guidelines. 2020. January.

52. Wong $\mathrm{H}$. et al. A comparison of high and standard blood transfusion volumes in premature infants // Acta Paediatr. 2005. Vol. 94 N 5. P. 624-625.

53. Paul D.A. et al. Transfusion volume in infants with very low birth weight: a randomized trial of 10 versus $20 \mathrm{ml} / \mathrm{kg} / / \mathrm{J}$. Pediatr. Hematol. Oncol. 2002. Vol. 24, N 1. P. 43-46.

54. Gibson B.E., Todd A., Roberts I., Pamphilon D., Rodeck C., BoltonMaggs P. et al. Transfusion guidelines for neonates and older children $/ / \mathrm{Br}$ J. Haematol. 2004. Vol. 124, N 4. P. 433-453.

55. National comparative audit of the use of red cells in neonates and children 2010 // National Comparative Audit Blood Transfusion. 2010 .

56. Борисова И.П., Амитриев А.В., Морщакова Е.Ф. Ранняя анемия недоношенных : профилактика и лечение // Вопросы гематологии/онко^огии и иммунопатологии в педиатрии. 2004. т. 3, № 1. С. 27-31.

57. Robinson S. et al. The administration of blood components: a British Society for Haematology Guideline // Transfus. Med. 2018. Vol. 28, N 1. P. 3-21.

58. 2020 Surveillance of Blood Transfusion. Blood Transfusion NICE Guideline [NG24]. London : National Institute for Health and Care Excellence (UK), 2015. 117 p.

59. Ohlsson A., Aher S.M. Early erythropoiesis-stimulating agents in preterm or low birth weight infants // Cochrane Database Syst. Rev. 2020. Vol. 2. CD004863.

60. Ohls R.K., Christensen R.D., Kamath-Rayne B.D., Rosenberg A Wiedmeier S.E., Roohi M. et al. A Randomized, masked, placebo-controlled study of darbepoetin alfa in preterm infants // Pediatrics. 2013. Vol. 132, N 1. P. $119-127$.

61. Christensen R.D., Lambert D.K., Richards D.S. Estimating the nucleated red blood cell "emergence time" in neonates // J. Perinatol. 2014. Vol. 34. P. 116-119.

62. Warwood T.L. et al. Single-dose darbepoetin administration to anemic preterm neonates // J. Perinatol. 2005. Vol. 25. P. $725-$ 730.

63. Patel S., Ohls R.K. Darbepoetin administration in term and preterm neonates // Clin. Perinatol. 2015. Vol. 42, N 3. P. 557-566.

64. Шарафутаинова А.Р., Балашова Е.Н., Ионов О.В., Киртбая А.Р., Голубцова Ю.М., Зубков В.В. и Ар. Эффективность применения раз мичных схем терапии рекомбинантным человеческим эритропоэтином у детей с очень низкой и экстремально низкой массой тела // Вопрось гематологии/онкологии и иммунопатологии в педиатрии. 2019. Vol. 18, № 2. P. $75-82$.

65. Meyer M.P., Meyer J.H., Commerford A., Hann F.M., Sive A.A. Moller G. et al. Recombinant human erythropoietin in the treatment of the anemia of prematurity: results of a double-blind, placebo-controlled study // Pediatrics. 1994. Vol. 93, N 6. P. 918-923.

66. Donato $\mathrm{H}$. et al. Effect of early versus late administration of human recombinant erythropoietin on transfusion requirements in premature infants: results of a randomized, placebo-controlled, multicenter trial // Pediatrics. 2000. Vol. 105, N 5. P. 1066-1072.

67. Ohls R.K. et al. The effect of erythropoietin on the transfusion requirements of preterm infants weighing 750 grams of less: a randomized, double-blind, placebo-controlled study // J. Pediatr. 1997. Vol. 131, N 5. P. 661-665.

68. Потапова В.Е., Аысенко И.М., Журавлева М.Н., Меховни кова А.А. Кминическая оценка особенностей течения ранней анемии недоношенных и эффективности ее терапии у новорожденных низких гестационных сроков // Охрана материнства и Аетства. 2016. Т. 2, № 28. C. 16-19.

69. Ronnholm K.A.R., Siimes M.A. Haemoglobin concentration depends on protein intake in small preterm infants fed human milk // Arch. Dis. Child. 1985. Vol. 60, N 2. P. 99-104.

70. Антонов А.Г., Буров А.А., Володин Н.Н., Горев В.В., Аепярев А.Н и Ар. Реанимация и стабилизация состояния новорожденных Аетей в родильном зале. Методическое письмо / поА реА. Е.Н. Байба риной // Неонатология: новости, мнения, обучение. 2020. Т. 8, № 1 (27) C. 34-52.

71. Fogarty M. et al. Delayed vs early umbilical cord clamping for pre term infants: a systematic review and meta-analysis // Am. J. Obstet. Gy necol. 2018. Vol. 218, N 1. P. 1-18.

72. van Rheenen P.F., Gruschke S., Brabin B.J. Delayed umbilical cord clamping for reducing anaemia in low birthweight infants: Implications for developing countries // Ann. Trop. Paediatr. 2006. Vol. 26, N 3. P. 157-167.

73. Widness J.A. et al. Reduction in red blood cell transfusions among preterm infants: results of a randomized trial with an in-line blood gas and chemistry monitor // Pediatrics. 2005. Vol. 115, N 5. P. 1299-1306.

74. Rosebraugh M.R. et al. A mathematical modeling approach to quantify the role of phlebotomy losses and need for transfusions in neonatal anemia // Transfusion. 2013. Vol. 53, N 6. P. 1353-1360.

75. Christensen R.D., Carroll P.D., Josephson C.D. Rvidence-based advances in transfusion practice in neonatal intensive care units // Neonatology. 2014. Vol. 106, N 3. P. 245-253.

76. Brener Dik P.H. et al. Impact of the volume of blood collected by phlebotomy on transfusion requirements in preterm infants with birth weight of less than 1500 g. A quasi-experimental study // Arch. Argent. Pediatr. 2020. Vol. 118, N 2. P. 109-116.

77. Jin H.X. et al. Early and late iron supplementation for low birth weight infants: a meta-analysis // Ital. J. Pediatr. 2015. Vol. 41, N 1. P. 1-10.

78. Long $\mathrm{H}$. et al. Benefits of Iron supplementation for low birth weight infants: a systematic review // BMC Pediatr. 2012. Vol. 12. P. 99.

79. Mills R.J., Davies M.W. Enteral iron supplementation in preterm and low birth weight infants // Cochrane Database Syst. Rev. 2012. Vol. 5. CD005095

80. Rao R., Georgieff M.K. Iron therapy for preterm infants // Clin. Perinatol. 2009. Vol. 36, N 1. P. 27-42.

81. MacQueen B.C. et al. Iron supplements for infants at risk for iron deficiency // Glob. Pediatr. Health. 2017. Vol. 4

82. Moorthy D. et al. The impact of nutrition-specific and nutritionsensitive interventions on hemoglobin concentrations and anemia: a metareview of systematic reviews // Adv. Nutr. 2020. Vol. 11, N 6. P. 16311645

83. Domellöf M. Meeting the iron needs of low and very low birth weight infants // Ann. Nutr. Metab. 2017. Vol. 71, N 3. P. 16-23.

84. Gomella T.L., Eyal F.G., Fayez B.-M. Gomella's Neonatology. 8th ed. McGraw-Hill Education, 2020. 1441 p.

85. Zipursky A., Brown E.J., Watts J., Milner R., Rand C., Blanchette V.S. et al. Oral vitamin E supplementation for the prevention of anemia in premature infants: a controlled trial // Pediatrics. 1987. Vol. 79, N 1. P. 61-68.

86. Fermanian J., Salmon D., Olive G., Zambrowski S., Rossier A., Caldera R. Comparaison en double aveugle de la vitamine e au placebo dans la prévention de l'anémie de l'enfant de faible poids de naissance a la 7e semaine de vie: essai thérapeutique // Nouv. Rev. Fr. Hematol. Blood Cells. 1976. Vol. 16, N 2. P. 245-254.

87. Brion L.P., Bell E.F., Raghuveer T.S. Vitamin E supplementation for prevention of morbidity and mortality in preterm infants // Cochrane Database Syst. Rev. 2003. Vol. 4. CD003665.

88. Нароган М.В., Аазарева В.В., Рюмина И.И., Ведихина И.А Значение фолатов Аля зАоровья и развития ребенка // Акушерство и гинекология. 2019. № 8. С. 46-52.

89. Revakova T., Revak O., Vasilenkova A., Behulova D., Brucknerova I. Amount of folic acid in different types of nutrition used in the neonata period // Bratisl. Lek. List. 2015. Vol. 116, N 6. P. 349-353.

90. Jyothi $\mathrm{S}$. et al. Red cell folate and plasma homocysteine in preterm infants // Neonatology. 2007. Vol. 92, N 4. P. 264-268. 
91. Oncel M.Y. et al. Is folic acid supplementation really necessary in preterm infants $\leq 32$ weeks of gestation? // J. Pediatr. Gastroenterol. Nutr. 2014. Vol. 58, N 2. P. $188-192$.

92. Çakmak Çelik F. et al. Assessment of different folic acid supplementation doses for low-birth-weight infants // Turk. Pediatri Ars. 2016. Vol. 51, N 4. P. 210-216.
93. Программа оптимизации вскармливания Аетей первого года жизни в Российской Федерации. Москва : ФГАУ НМИЦ зАоровья Аетей Минзарава России, 2019. 112 с.

94. Pasricha S.R. et al. Effect of daily iron supplementation on health in children aged 4-23 months: a systematic review and meta-analysis of randomised controlled trials // Lancet Glob. Health. 2013. Vol. 1, N 2. P. e77-e86.

\section{REFERENCES}

1. Colombatti R., Sainati L., Trevisanuto D. Anemia and transfusion in the neonate. Semin Fetal Neonatal Med. 2016; 21 (1): 2-9.

2. Sakharova E.S., Keshishian E.S., Alyamovskaya G.A. Anemia in premature babies. Pathogenesis, diagnosis, treatment and prevention. Meditsinskiy sovet [Medical Council]. 2015; (6): 10-7. DOI: https://doi. org/10.21518/2079-701X-2015-6-10-17 (in Russian)

3. Widness J.A. Pathophysiology of anemia during the neonatal period, including anemia of prematurity. Neoreviews. 2008; 9 (11): 520-5.

4. Luchtman-Jones L., Schwartz W.D. The blood and hematopoietic system. Edited by A.A. Fanaroff, R.J. Martin. Neonatal-Perinatal Medicine. Disorders of Fetus and Infant. 7th ed. St Louis: Mosby, 2002: 1182-254.

5. Widness J.A. Pathophysiology, diagnosis, and prevention of neonatal anemia. Neoreviews. 2000; 1 (4): 61.

6. Papayan A.V., Zhukova L.Yu. Anemia in children: clinical practice guidelines. Saint Petersburg: Piter, 2001: 384 p. (Series "Modern Medicine"). ISBN 5-272-00364-0 (in Russian)

7. Dallman P.R. Blood and blood-forming tissues. Eds by A. Rudolph. Pediatrics. 16th ed. New York: Appleton-Century-Crofts, 1977: 1111.

8. Brown M.S., et al. Decreased response of plasma immunoreactive erythropoietin to "available oxygen" in anemia of prematurity. J Pediatr. 1984; 105 (5): 793-8.

9. New H.V., et al. Guidelines on transfusion for fetuses, neonates and older children. Br J Haematol. 2016; 175 (5): 784-828.

10. Von Lindern J.S., Lopriore E. Management and prevention of neonatal anemia: current evidence and guidelines. Expert Rev Hematol. 2014; 7 (2): 195-202.

11. de Freitas B.A.C., et al. Micronutrient supplementation adherence and influence on the prevalences of anemia and iron, zinc and vitamin a deficiencies in preemies with a corrected age of six months. Clinics. 2016; 71 (8): 440-8.

12. Aher S., Malwatkar K., Kadam S. Neonatal anemia. Semin Fetal Neonatal Med. 2008; 13 (4): 239-47.

13. Dallman P.R. Anemia of prematurity. Annu Rev Med. 1981; 32 $143-60$.

14. Girelli G., et al. Recommendations for transfusion therapy in neonatology. Blood Transfus. 2015; 13 (3): 484-97.

15. Bizzarro M.J., Colson E., Ehrenkranz R.A. Differential diagnosis and management of anemia in the newborn. Pediatr Clin North Am. 2004; 51: $1087-107$.

16. Jopling J., et al. Reference ranges for hematocrit and blood hemoglobin concentration during the neonatal period: data from a multihospital health care system. Pediatrics. 2009; 123 (2): e333-7.

17. Obladen M., Sachsenweger M., Stahnke M. Blood sampling in very low birth weight infants receiving different levels of intensive care. Eur J Pediatr. 1988; 147 (4): 399-404.

18. Madsen L.P., et al. Impact of blood sampling in very preterm infants. Scand J Clin Lab Invest. 2000; 60 (2): 125-32.

19. Takahashi D., et al. Effect of transfusion on the venous blood lactate level in very low-birthweight infants. Pediatr Int. 2009; 51 (3): 321-5.

20. Dani C., et al. Effects of red blood cell transfusions during the first week of life on acid-base, glucose, and electrolytes in preterm neonates. Transfusion. 2008; 48 (11): 2302-7.

21. Nadeem M., Clarke A., Dempsey E.M. Day 1 serum lactate values in preterm infants less than 32 weeks gestation. Eur J Pediatr. 2010; 169 (6): $667-70$.

22. Izraeli S., et al. Lactic acid as a predictor for erythrocyte transfusion in healthy preterm infants with anemia of prematurity. J Pediatr. 1993; 122 (4): 629-31.

23. Ross M.P., Christensen R.D., Rothstein G., Koenig J.M., Simmons M.A., Noble N.A., et al. A randomized trial to develop criteria for administering erythrocyte transfusions to anemic preterm infants 1 to 3 months of age. J Perinatol. 1989; 9 (3): 246-53.
24. Kanmaz H.G., et al. Effects of red cell transfusion on cardiac output and perfusion index in preterm infants. Early Hum Dev. 2013; 89 (9): 683-6

25. Dallman M.D., et al. Changes in transfusion practice over time in the PICU. Pediatr Crit Care Med. 2013; 14 (9): 843-50.

26. Abdelghaffar S., et al. Red blood transfusion in preterm infants: changes in glucose, electrolytes and acid base balance. Asian J Transfus Sci. 2012; 6 (1): 36-41

27. Wang M. Iron deficiency and other types of anemia in infants and children. Am Fam Physician. 2016; 93 (4): 270-8.

28. Joy R., et al. Early versus late enteral prophylactic iron supplementation in preterm very low birth weight infants: a randomised controlled trial. Arch Dis Child Fetal Neonatal Ed. 2014; 99 (2): F105-9.

29. McCarthy E.K., Dempsey E.M., Kiely M.E. Iron supplementation in preterm and low-birth-weight infants: a systematic review of intervention studies. Nutr Rev. 2019; 77 (12): 865-77.

30. Schiza V., et al. Serum transferrin receptor, ferritin, and reticulocyte maturity indices during the first year of life in "large" preterm infants. Eur J Haematol. 2007; 79 (5): 439-46.

31. Lorenz L., et al. Reference ranges of reticulocyte haemoglobin content in preterm and term infants: a retrospective analysis. Neonatology 2017; 111 (3): 189-94.

32. Diab Y.A., Wong E.C.C., Luban N.L.C. Massive transfusion in children and neonates. Br J Haematol. 2013; 161 (1): 15-26.

33. Sihler K.C., Napolitano L.M. Complications of massive transfusion. Chest. 2010; 137 (1): 209-20.

34. Order of the Ministry of Health of the Russian Federation dated 02.04.2013 No. 183n. "The rules of clinical use of donor blood and/or its components" (registered Russian Ministry of Justice, 2013). (in Russian)

35. MacDonald M.G., Ramasethu J.R.-B.K. Atlas of Procedures in Neonatology. 5th ed. Lippincott Williams and Wilkins, Wolter Kluwer, 2013 $429 \mathrm{p}$.

36. Mozzini C., et al. Ultrasound as first line step in anaemia diagnostics. Mediterr J Hematol Infect Dis. 2019; 11 (1): 1-10.

37. Singh Y., et al. International evidence-based guidelines on Point of Care Ultrasound (POCUS) for critically ill neonates and children issued by the POCUS Working Group of the European Society of Paediatric and Neonatal Intensive Care (ESPNIC). Crit Care. 2020; 24 (1): 1-16.

38. Joshi S., Mulinge I., Kamat M. An extremely premature neonate with severe anemia. J Neonatal Surg. 2017; 6 (2): 33.

39. Mutlu M., et al. Adrenal hemorrhage in newborns: a retrospective study. World J Pediatr. 2011; 7 (4): 355-7.

40. Kluckow M., Evance N. Low superior vena cava flow and intraventricular haemorrhage in preterm infants. Arch Dis Child Feta Neonatal Ed. 2000; 82 (3): 188-94

41. Papile L.A., et al. Incidence and evolution of subependymal and intraventricular hemorrhage: a study of infants with birth weights less than 1,500 gm. J Pediatr. 1978; 92 (4): 529-34.

42. Hintz S.R., et al. Interobserver reliability and accuracy of crania ultrasound scanning interpretation in premature infants. J Pediatr. 2007; 150 (6): 592-6.

43. Toti M.S., et al. Adrenal hemorrhage in newborn: how, when and why- from case report to literature review. Ital J Pediatr. 2019; 45 (1): 1-8.

44. Azarow K., et al. Multidisciplinary evaluation of the distended abdomen in critically ill infants and children: the role of bedside sonography. Pediatr Surg Int. 1998; 13 (5-6): 355-9.

45. Sweet D.G., et al. European Consensus Guidelines on the Management of Respiratory Distress Syndrome - 2019 Update. Neona tology. 2019; 115 (4): 432-50.

46. Von Lindern J.S., et al. Long-term outcome in relationship to neonatal transfusion volume in extremely premature infants: a comparative cohort study. BMC Pediatr. 2011; 11: 48. 
47. Venkatesh V., et al. How we decide when a neonate needs a transfusion. Br J Haematol. 2013; 160 (4): 421-33.

48. Venkatesh V., et al. The safety and efficacy of red cell transfusions in neonates: a systematic review of randomized controlled trials. $\mathrm{Br}$ J Haematol. 2012; 158 (3): 370-85.

49. Whyte R., Kirpalani H. Low versus high haemoglobin concentration threshold for blood transfusion for preventing morbidity and mortality in very low birth weight infants. Cochrane Database Syst Rev. 2011; 11: CD000512.

50. Strauss R.G. Anaemia of prematurity: pathophysiology and treatment. Blood Rev. 2010; 24 (6): 221-5.

51. Nurse S.N. Red Blood Cell Transfusion for Neonates - Guidelines. 2020. January.

52. Wong $H_{\text {. }}$, et al. A comparison of high and standard blood transfusion volumes in premature infants. Acta Paediatr. 2005; 94 (5): 624-5.

53. Paul D.A., et al. Transfusion volume in infants with very low birth weight: a randomized trial of 10 versus $20 \mathrm{ml} / \mathrm{kg}$. J Pediatr Hematol Oncol. 2002; 24 (1): 43-6.

54. Gibson B.E., Todd A., Roberts I., Pamphilon D., Rodeck C., BoltonMaggs $\mathrm{P}$., et al. Transfusion guidelines for neonates and older children. $\mathrm{Br}$ J Haematol. 2004; 124 (4): 433-53.

55. National comparative audit of the use of red cells in neonates and children 2010. In: National Comparative Audit Blood Transfusion. 2010.

56. Borisova I.P., Dmitriev A.V., Morshchakova E.F. Early anemia of premature newborns: prevention and treatment. Voprosy gematologii/ onkologii i immunopatologii $v$ pediatrii [Problems of Hematology/ Oncology and Immunopatology in Pediatrics]. 2004; 3 (1): 27-31. (in Russian)

57. Robinson S., et al. The administration of blood components: a British Society for Haematology Guideline. Transfus Med. 2018; 28 (1): 3-21.

58. 2020 Surveillance of Blood Transfusion. Blood Transfusion NICE Guideline [NG24]. London: National Institute for Health and Care Excellence (UK), 2015: $117 \mathrm{p}$.

59. Ohlsson A., Aher S.M. Early erythropoiesis-stimulating agents in preterm or low birth weight infants. Cochrane Database Syst Rev. 2020; 2: CD004863.

60. Ohls R.K., Christensen R.D., Kamath-Rayne B.D., Rosenberg A., Wiedmeier S.E., Roohi M., et al. A Randomized, masked, placebo-controlled study of darbepoetin alfa in preterm infants. Pediatrics. 2013; 132 (1): 119-27.

61. Christensen R.D., Lambert D.K., Richards D.S. Estimating the nucleated red blood cell "emergence time" in neonates. J Perinatol. 2014; 34: 116-9.

62. Warwood T.L., et al. Single-dose darbepoetin administration to anemic preterm neonates. J Perinatol. 2005; 25: 725-30.

63. Patel S., Ohls R.K. Darbepoetin administration in term and preterm neonates. Clin Perinatol. 2015; 42 (3): 557-66.

64. Sharafutdinova D.R., Balashova E.N., Ionov O.V., Kirtbaya A.R., Golubtsova Yu.M., Zubkov V.V., et al. The recombinant human erythropoietin therapy for extremely and very low birth weight infants. Voprosy gematologii/ onkologii i immunopatologii v pediatrii [Problems of Hematology/Oncology and Immunopatology in Pediatrics]. 2019; 18 (2): 75-82. DOI: https://doi. org/10.24287/1726-1708-2019-18-2-75-82 (in Russian)

65. Meyer M.P., Meyer J.H., Commerford A., Hann F.M., Sive A.A., Moller G., et al. Recombinant human erythropoietin in the treatment of the anemia of prematurity: results of a double-blind, placebo-controlled study. Pediatrics. 1994; 93 (6): 918-23.

66. Donato $H_{\text {., }}$ et al. Effect of early versus late administration of human recombinant erythropoietin on transfusion requirements in premature infants: results of a randomized, placebo-controlled, multicenter trial. Pediatrics. 2000; 105 (5): 1066-72.

67. Ohls R.K., et al. The effect of erythropoietin on the transfusion requirements of preterm infants weighing 750 grams of less: a randomized, double-blind, placebo-controlled study. J Pediatr. 1997; 131 (5): 661-5.

68. Potapova V.E., Lysenko I.M., Zhuravleva L.N., Mekhovnikova D.A. Clinical evaluation of peculiarities of early anemia of prematurity and the effectiveness of its therapy in newborns of low gestational term. Okhrana materinstva i detstva [Protection of Motherhood and Childhood]. 2016; 2 (28): 16-9. (in Russian)

69. Ronnholm K.A.R., Siimes M.A. Haemoglobin concentration depends on protein intake in small preterm infants fed human milk. Arch Dis Child. 1985; 60 (2): 99-104.
70. Neonatal resuscitation and stabilization in delivery room Methodological letter. Eds by E.N. Baybarina. Neonatologiya: novosti, mneniya, obuchenie [Neonatology: News, Opinions, Training]. 2020; 8 (1) 34-52. (in Russian)

71. Fogarty M., et al. Delayed vs early umbilical cord clamping for preterm infants: a systematic review and meta-analysis. Am J Obstet Gynecol. 2018; 218 (1): 1-18.

72. van Rheenen P.F., Gruschke S., Brabin B.J. Delayed umbilical cord clamping for reducing anaemia in low birthweight infants: Implications for developing countries. Ann Trop Paediatr. 2006; 26 (3): 157-67.

73. Widness J.A., et al. Reduction in red blood cell transfusions among preterm infants: results of a randomized trial with an in-line blood gas and chemistry monitor. Pediatrics. 2005; 115 (5): 1299-306.

74. Rosebraugh M.R., et al. A mathematical modeling approach to quantify the role of phlebotomy losses and need for transfusions in neonatal anemia. Transfusion. 2013; 53 (6): 1353-60.

75. Christensen R.D., Carroll P.D., Josephson C.D. Rvidence-based advances in transfusion practice in neonatal intensive care units. Neonatology. 2014; 106 (3): 245-53.

76. Brener Dik P.H., et al. Impact of the volume of blood collected by phlebotomy on transfusion requirements in preterm infants with birth weight of less than $1500 \mathrm{~g}$. A quasi-experimental study. Arch Argent Pediatr. 2020; 118 (2): 109-16.

77. Jin H.X., et al. Early and late iron supplementation for low birth weight infants: a meta-analysis. Ital J Pediatr. 2015; 41 (1): 1-10.

78. Long $\mathrm{H}_{\text {., }}$ et al. Benefits of Iron supplementation for low birth weight infants: a systematic review. BMC Pediatr. 2012; 12: 99.

79. Mills R.J., Davies M.W. Enteral iron supplementation in preterm and low birth weight infants. Cochrane Database Syst Rev. 2012; 5 : CD005095.

80. Rao R., Georgieff M.K. Iron therapy for preterm infants. Clin Perinatol. 2009; 36 (1): 27-42.

81. MacQueen B.C., et al. Iron supplements for infants at risk for iron deficiency. Glob Pediatr Health. 2017; 4.

82. Moorthy D., et al. The impact of nutrition-specific and nutritionsensitive interventions on hemoglobin concentrations and anemia: a metareview of systematic reviews. Adv Nutr. 2020; 11 (6): 1631-45.

83. Domellöf M. Meeting the iron needs of low and very low birth weight infants. Ann Nutr Metab. 2017; 71 (3): 16-23.

84. Gomella T.L., Eyal F.G., Fayez B.-M. Gomella's Neonatology. 8th ed. McGraw-Hill Education, 2020: 1441 p.

85. Zipursky A., Brown E.J., Watts J., Milner R., Rand C., Blanchette V.S., et al. Oral vitamin E supplementation for the prevention of anemia in premature infants: a controlled trial. Pediatrics. 1987; 79 (1): $61-8$.

86. Fermanian J., Salmon D., Olive G., Zambrowski S., Rossier A. Caldera R. Comparaison en double aveugle de la vitamine e au placebo dans la prévention de l'anémie de l'enfant de faible poids de naissance a la 7 e semaine de vie: essai thérapeutique. Nouv Rev Fr Hematol Blood Cells. 1976; 16 (2): 245-54.

87. Brion L.P., Bell E.F., Raghuveer T.S. Vitamin E supplementation for prevention of morbidity and mortality in preterm infants. Cochrane Database Syst Rev. 2003; 4: CD003665.

88. Narogan M.V., Lazareva V.V., Ryumina I.I., Vedikhina I.A. The value of folates for child health and development. Akusherstvo i ginekologiya [Obstetrics and Gynecology]. 2019; (8): 46-52. (in Russian)

89. Revakova T., Revak O., Vasilenkova A., Behulova D., Brucknerova I. Amount of folic acid in different types of nutrition used in the neonatal period. BratisI Lek List. 2015; 116 (6): 349-53.

90. Jyothi S., et al. Red cell folate and plasma homocysteine in preterm infants. Neonatology. 2007; 92 (4): 264-8.

91. Oncel M.Y., et al. Is folic acid supplementation really necessary in preterm infants $\leq 32$ weeks of gestation? J Pediatr Gastroenterol Nutr 2014; 58 (2): 188-92.

92. Çakmak Çelik F., et al. Assessment of different folic acid supplementation doses for low-birth-weight infants. Turk Pediatri Ars. 2016 51 (4): 210-6.

93. Program for optimizing the feeding of children of the first year of life in the Russian Federation. Moscow : FGAU "NMITs zdorov'ya detey" Minzdrava Rossii, 2019: $112 \mathrm{p}$ (in Russian)

94. Pasricha S.R., et al. Effect of daily iron supplementation on health in children aged 4-23 months: a systematic review and metaanalysis of randomised controlled trials. Lancet Glob. Health. 2013; 1 (2) e77-86. 